\title{
Children's Day-care in Finland
}

\author{
By JOUKO HULKKO
}

Finnish Population and Family Welfare League Väestöliitto

Urbanisation, industrialisation, the increasing entry of women into gainful work, the diminishing age for entering into marriage, the extended period of professional training and the achievement of greater equality by women, have in combination brought about a growing need for organised day-care of children. The organisation of such care in Finland has become a topical question largely because parents, by reason of their work, have not themselves been in a position to give their children the necessary attention. But with the day-care of children, it is also a matter of providing impulses, and satisfying the psychical, physical, emotional and social requirements of children.

According to the stipulations of the act on child protection, the municipalities are responsible, at need, to establish and maintain institutions that support and complement the home upbringing of children, or to provide assistance to institutions founded on private initiative. The municipalities have also established kindergartens intended for children of three to six years of age, for half-day or whole-day use. Special institutions, nursery schools, have been set up for children of less than three years of age. For the physically handicapped, braindamaged or other deviating children, special institutions have become available. Apart from these, private initiative has brought into being so-called dayhomes for children of less than seven years of age, and some day-homes for schoolchildren.

During the last few years, directed family day-care has come into existence: by this is meant child care in private families supervised by the municipality.

In Finland, there are about 490000 children under school age: of these, 150000 have mothers in employment outside the home. In 1970, day-care accommodation existed for about 37000 children, to which should be added 10000 places in day-nurseries open for some few hours a day, or days a week. Of the day-care places, 74 per cent are in the muncipal institutions, and 26 per cent in those of private associations. Some 85 per cent of day-care accommodation is located in the towns. Of those children who lack day-care places, and whose parents are both in employment, approximately 25 per cent are tended by maids, relatives provide care for 25 per cent, and other families about 10 per cent. A small proportion of the children accompany their mothers to the place of work, and the remainder are at home, either with older brothers or sisters, or alone.

During the closing years of the sixties, the question of child care was discussed by several state-appointed committees, most recently in the day-care committee appointed by the Cabinet following a parliamentary decision. The report of this committee was completed on 30 September 1971. The tasks of the committee included clarification of the need of children's day-care now and in the near future, purposeful forms for its realisation and the expenditure involved, the need of state support, and its fair distribution, along with support for childcare at home.

In parallel with the day-care committee, there is working a pre-school 
committee appointed by the Cabinet on July 4, 1970, entrusted with the task of determining the aims of preschool education, along with the formulation of a general plan for its development, together with the requisite proposals for legislation and educational plans. Through the agency of the committee, educational proposals have been formulated for experimental activity in respect of pre-schooling: this has begun in a number of places. In its work, the day-care committee has taken account of the tasks entrusted to the preschool committee, and has accordingly not taken the pre-school question in its proposals, even though these are closely connected one with the other when it is a matter of care and education of children between the ages of four and six.

\section{Problems in the realisation of day-care}

Approximately the same numbers of children are born in the towns and rural areas. By virtue of the breakthrough of family planning, childbirth has been almost completely transferred to young women: in the year 1968, women aged less than 30 years of age gave birth to 74.7 per cent of all children, and those under 24 years of age 48.7 per cent. During the course of the last 20 years, the age for entering upon marriage has declined. The median age of marriage for wome's in 1968 was 21.2 , and for men 22.8. When a comparison is made between the age of marriage and the time of birth of children, it can be established that the first child is born 9.5 months after the date of marriage, the second child 2 years after the first, and the third and fourth at intervals of about three years. A proportion of 65.8 per cent of all children are born during the first four years of marriage. By tradition, the tending of children has been one ot the tasks of the mother, and thus the need of arranged child day-care is dependent upon how commonly the mother is engaged in employment outside the home. The participation of women in gainful employment has increased by reason of the extended period of training and urbanisation as follows:

\begin{tabular}{|c|c|c|}
\hline 1910 & 36.4 & r cent \\
\hline 1920 & 39.6 & $»$ \\
\hline 1930 & 40.8 & 》 \\
\hline 1940 & 43.0 & $»$ \\
\hline 1950 & 40.7 & " \\
\hline 1960 & 57.6 & $\gg$ \\
\hline 1968 & 52.3 & » \\
\hline
\end{tabular}

Naturally enough, the increased number of women employed outside their homes receives a contribution from the desire to earn extra money, especially as the average annual income of the young, those under 25 years of age, is clearly lower than that of the other employable population. In the lower social groups, an increase in income constitutes the motive for the gainful employment of the mother, and in the upper groups (those with academic graduation) the maintenance of professional skill. In various places, investigations made have demonstrated that more than one half of mothers engaged in employment give economic factors as the main reason. A special group of children in need of day-care is made up by those whose parents are engaged in studies. Students' marriages are becoming more common.

For the most part, childbirth occurs during a period when the parents are young, and their income level particularly low. At the same time also arise the cost involved in finding a place to live, the acquisition of a house, and frequently the costs of education as well.

Although the frequency of marriage has attained a high level in Finland, fertility has declined markedly, both proportionately and absolutely (cf. Figure 2 p. 23). During the years 1969 and 1970 , emigration was greater than the increase in the population aged is and over. It has been assumed that if emigration had not appeared the surplus 
of births in 1970 would have been some 6-7 per cent higher.

In Finland, the decline in fertility has occurred at a time when the national income has risen steadily. During this period of development, however, the position of the family, and particularly that of young married couples, has deteriorated in relation to that of others: this is also shown by the family policy proportion of the national income in 1950 being 3.3 per cent, falling to 2.2 per cent in 1969 , or by more than a third. In Finland a total fertility rate of 2.3 per cohort should be sufficient if the population figure is to be kept constant. During the year 1969 the number of children per woman of fertile age was 1.90 .

\section{The principles of objectivity}

The day-care service for children constitutes a part of the family-politic support through which the community endeayours to raise the situation of families with children in relation to those without children to maintain.

A well-tended family policy permits of influence being exercised upon the structure of both the population and the coming labour force available, and, by means of guaranteeing opportunities for an even development of population, being able to forecast the labour force policy that should be implemented. For its part, this exerts a favourable effect upon the possibilities of development of cultural and economic life.

The expenditure involved in the care of children varies, dependent upon the way in which it is organised. If consideration is given to the direct expenditures of the community, child care at home is the least expensive, and care in a municipal institution the most expensive of care. For the child day-care institutions founded during the years 1969 and 1970, the building costs per square metres were 799-1,139 Fmk., dependent upon the locality. (10 Fmk. $=£ 1$ ). No establishment costs are entailed in supervised family child daycare. In institutions, the costs per month and per child amount to $200-380$, and in supervised family care $150-230 \mathrm{Fmk}$.

In a sparsely-populated country such as Finland, it is not purposeful to build institutions in thinly populated areas and small villages. In cases of this type, supervised family day-care offers a flexible opportunity for achievement of a solution. From the standpoint of the community, the tending of children at home, in family day-care, or in daycare institutions, has no difference in value. In all forms of children's care, the work implies participation in productive activity, since it constitutes the production of coming labour power. Accordingly, no form of care should be favoured at the expense of the others. To achieve a complete solution which takes into account the local variations, the differing circumstances and needs of families, and which offers possibilities of choice, the day-care committee made a proposal in its report which diverges from all earlier proposals presented in Finland.

The committee formulated proposals for legislation on children's maintenance and on child day-care. The bill is a complete whole, and in it an endeavour has been made, in regard to support by the community, to place on terms of equality the care of the child at home and the care given outside the home. In those cases in which the child's parents wish to tend to the child at home, or where the community can not offer care outside the home, child maintenance has been given by way of compensation which in part corresponds to the care of the child in an establishment or in supervised family care. In the event that the parents with to place their child in a day-care institution, or in supervised family daycare, they would use the sum given for child maintenance in payment for these services. By this means, it has been desired that possibilities of choice be made available for both the parents and the child. 
With a view to providing assistance in raising the economic position of the families with children, the committee has proposed that maintenance for children under school age should be taken into use. The committee proposed that child maintenance, payable monthly, would amount to $175 \mathrm{Fmk}$. in respect of children less than one year of age, $100 \mathrm{Fmk}$. for those of less than three years, and $75 \mathrm{Fmk}$. from three years until school age. The intention of child maintenance is that of furthering the opportunities available to parents to stay at home themselves and tend to their children, especially during the early years of life of the child, or on the other hand to better their economic position and enable them to acquire good child day-care.

In the work of the committee, it has been established that the current, deficient legislation which controls daycare activity does not provide adequate foundation for the development of activity. The intention of day-care is, apart from the substitute care proper, also to complement the upbringing given to children at home by the parents with impulses that promote development. The impulse-giving activity that supports the acts of children's upbringing at home should be developed in such a way that all children participate in them, irrespective of locality and other circumstances, at least in some stage before the time comes to attend school.

The attainment of these aims presumes that the service available is vigorously augmented through the agency of the community. The committee has proposed that institutional activity should be developed in such a way that, in place of large, sparsely located institutions, attempts should be made to bring into existence small, homely day-care institutions near the child's own home. The day home with a friendly note for children should in its work observe to the greatest extent possible the individual needs of each child, both in regard to the care provided, and the amount of time devoted to it. Alongside the institutional activity, endeavours should be made to enlarge special forms of open care, such as supervised family day-care. An effective start should be made on experiments with forms of day-care appropriate for different conditions, and also to engage in investigations which shed light upon the influences exercised by day-care.

In the opinion of the committee, the financial opportunities available to the municipalities for augmenting the daycare service should be improved. It has decided to propose that the system of state support for day-care should be brought to realisation in such a way that state assistance would be paid out by application of the same rules for both institutional and open care. The lawful state assistance would apply to the costs of running the institutions, and would vary between 70 and 90 per cent of the approved costs, dependent upon the means at the disposal of the municipalities. When the state assistance is calculated, deduction would be made from the costs of those amounts paid out by those tending the child. When the claims for compensation are adjusted, use is recommended of the same-price principle in such a way that the compensation claimed for the various froms of day-care would be mutually comparable. The payment of child maintenance creates possibilities for increasing the share of the persons taking care of the child, so that the lowest payment would be the same as child maintenance. As services increase, and can be offered to all population groups, it is purposeful to strive to observe also the capacity to pay by the parents when the extent of the compensation is decided.

\section{The bill - main administrative aspects}

The bill proposes that a child allowance be payable monthly, calculated from the beginning of the month in which maternity benefit ceases. The right to child maintenance ends during the 
month in which the child starts school. When the parents jointly care for the child, the right to draw the maintenance is vested in the mother. However, if the mother is prevented from drawing the maintenance, the father or other guardian may do so. Child maintenance is subject to state taxation, but not to municipal taxation. The allowance may not be distrained upon.

The highest instance for children's day care is the Ministry for Social and Health Affairs, with which works an advisory board for day-care. This advisory board is an advisory and planning body composed of experts in social policy, pedagogic care of the health, population matters, labour power and family policy: the members are appointed by the Council of State. The National Board of Social Welfare is responsible for the realisation, management and supervision of day-care.

The municipalities have to ensure that childrens' day-care is available to the extent and form of activity demanded by the circumstances. Municipalities should formulate a day-care plan.

In childrens' day-care institutions, termed "day homes" in the bill, at least five and at most 100 places should be available. The family day home should contain at most four children for every attendant, with the family's own children of less than seven years of age included. For the supervision of family day-care, the municipality should have sufficient staff available.

In addition, the bill has stipulations on the right to obtain state aid, and the supervision of its recipients. The minimum sum payable by parents for child care is equivalent to the amount of the child maintenance, although more can be collected from wealthier parents. The amount of the payment is confirmed by the municipal council within the limits of the instructions given by the $\mathrm{Na}$ tional Board of Social Welfare.

A private person or association professionally engaged in child day-care is obliged to report to the municipality before activity is begun, even if not in receipt of state aid. 